\title{
Relationships of self-identified cold tolerance and cold-induced vasodilatation in the finger
}

\author{
Joonhee Park, Joo-Young Lee \\ From 15th International Conference on Environmental Ergonomics (ICEE XV) \\ Portsmouth, UK. 28 June - 3 July 2015
}

\begin{abstract}
Introduction
Thermal environments in daily life, such as occupational cold exposure and the use of heating facilities and warm clothing, affect acclimatization to both cold and heat. Also, cold tolerance can be cognized by self-identified evaluation. Thermal life-style during daily life might be one of the factors which affect cold-induced vasodilatation (CIVD) when different degrees of thermal stimuli are considered. Therefore, this study investigated whether or not CIVD response is related to self-identified cold and heat tolerances which is attributable to thermal life-style.
\end{abstract}

\section{Methods}

A self-reported survey and a CIVD test were conducted with 9 males and 34 females. The self-reported questionnaire consisted of 28 questions about personal information and self-identified cold tolerance. Each question used a 4-point scale (1: strongly disagree, 2: disagree, 3: agree, and 4: strongly agree). The CIVD test consisted of 10-min resting, 30-min immersion $\left(3.8(0.3){ }^{\circ} \mathrm{C}\right)$ of the middle finger and 20-min recovery in climatic chamber $\left(27.9(0.1){ }^{\circ} \mathrm{C}\right)$. We used a CIVD definition of $>1.0{ }^{\circ} \mathrm{C}$ increase in finger skin temperature. As for CIVD variables, the following characteristics from finger skin temperature curves were examined: 1) Time in minutes until the onset of the first CIVD following immersion $\left.\left(t_{\text {onset }}\right), 2\right)$ finger skin temperature at which the first vasodilation occurred (Minimum finger temperature, $\left.T_{\text {min }}\right)$,3) period in minutes of the temperature rise for the first CIVD $\left.\left(\mathrm{t}_{\text {peak }}\right), 4\right)$ maximum finger skin temperature during the first vasodilation cycle $\left.\left(\mathrm{T}_{\max }\right), 5\right)$ mean finger skin temperature from the moment of the CIVD onset to the end of the cold immersion $\left(\mathrm{T}_{\text {mean }}\right)$,

\footnotetext{
* Correspondence: leex3140@snu.ac.kr

COM:FORT Laboratory, College of Human Ecology, Seoul National University,
} Seoul, Republic of Korea

\section{Discussion}

HSCT had more pronounced and quicker CIVD reactions and higher finger skin temperature when compared to LSCT. This is because HSCT has higher peripheral temperatures during local cold exposure when compared to LSCT. The result of faster $t_{\text {onset }}$ in HSCT shows that HSCT is the group that has a high level of cold tolerance. This also means that the group classification by selfidentified cold tolerance was quite applicable.

\section{Conclusion}

We proved that self-identification during daily life is significantly related to physiological responses. This result suggests that the level of individual cold tolerance can be evaluated by a standardized questionnaire on selfidentified thermal tolerance. Such convenient evaluations can be applied to schools or military camps to monitor people who are sensitive to cold on a screening stage of health check-ups. 


\section{Acknowledgements}

This work was supported by the National Research Foundation of Korea

(NRF) grant funded by the Korea government (MSIP) (No.2014

R1A2A2A03006522).

Published: 14 September 2015

doi:10.1186/2046-7648-4-S1-A57

Cite this article as: Park and Lee: Relationships of self-identified cold

tolerance and cold-induced vasodilatation in the finger. Extreme

Physiology \& Medicine 2015 4(Suppl 1):A57.

Submit your next manuscript to BioMed Central and take full advantage of:

- Convenient online submission

- Thorough peer review

- No space constraints or color figure charges

- Immediate publication on acceptance

- Inclusion in PubMed, CAS, Scopus and Google Scholar

- Research which is freely available for redistribution

Submit your manuscript at www.biomedcentral.com/submit
C Biomed Central 